\title{
Maternal vegetable intake during and after pregnancy
}

Alison Tovar ${ }^{1 *}$ (D) Jill L. Kaar ${ }^{2,5}$, Karen McCurdy³ ${ }^{3}$ Alison E. Field ${ }^{4}$, Dana Dabelea ${ }^{2,5}$ and Maya Vadiveloo ${ }^{1}$

\begin{abstract}
Background: Improved understanding of vegetable intake changes between pregnancy and postpartum may inform future intervention targets to establish healthy home food environments. Therefore, the goal of this study was to explore the changes in vegetable intake between pregnancy and the postnatal period and explore maternal and sociodemographic factors that are associated with these changes.

Methods: We examined sociodemographic, dietary, and health characteristics of healthy mothers 18-43y from the prospective Infant Feeding Practices II cohort $(n=847)$ (2005-2012). Mothers completed a modified version of the diet history questionnaire, a food-frequency measure, developed by the National Cancer Institute. We created four categories of mothers, those that were: meeting vegetable recommendations post- but not prenatally $(n=121$; improved intake), not meeting vegetable recommendations during pregnancy and postnatally $(n=370$; stable inadequate), meeting recommendations pre- but not postnatally ( $n=123$; reduced intake), and meeting recommendations at both time points $(n=233$; stable adequate). To make our results more relevant to public health recommendations, we were interested in comparing the improved vegetable intake group vs. stable inadequate vegetable intake group, as well as those that reduced their vegetable intake compared to the stable adequate vegetable intake group. Separate multivariable-adjusted logistic regression were used to examine sociodemographic predictors of improved vs. stable inadequate and reduced vs. stable adequate vegetable intake.
\end{abstract}

Results: Women with improved vegetable intake vs. stable inadequate smoked fewer cigarettes while women with reduced vegetable intake vs. stable adequate were more likely to experience less pregnancy weight gain. In adjusted models, employed women had greater odds of reduced vegetable intake $(\mathrm{OR}=1.6495 \% \mathrm{Cl}$ 1.14-2.36). In exploratory analyses, employment was associated with greater odds of reduced vegetable intake among lowincome $(\mathrm{OR}=1.79 ; 95 \% \mathrm{Cl} 1.03-3.1)$, but not higher income women $(\mathrm{OR}=1.31 ; 95 \%$ Cl 0.94-1.84). After further adjustment for paid maternity leave, employment was no longer associated with vegetable intake among lower income women (OR: 1.53; 95\% Cl: 0.76-3.05).

Conclusions: More women with reduced vs. stable adequate vegetable intake were lower income and worked full time. Improved access to paid maternity leave may help reduce disparities in vegetable quality between lower and higher income women.

Keywords: Vegetable intake, Pregnancy, Employment, Maternity leave

\footnotetext{
*Correspondence: Alison_tovar@uri.edu

${ }^{1}$ Department of Nutrition and Food Sciences, University of Rhode Island, 41

Lower College Road, Kingston, RI 02881, USA

Full list of author information is available at the end of the article
}

(c) The Author(s). 2019 Open Access This article is distributed under the terms of the Creative Commons Attribution 4.0 International License (http://creativecommons.org/licenses/by/4.0/), which permits unrestricted use, distribution, and reproduction in any medium, provided you give appropriate credit to the original author(s) and the source, provide a link to the Creative Commons license, and indicate if changes were made. The Creative Commons Public Domain Dedication waiver (http://creativecommons.org/publicdomain/zero/1.0/) applies to the data made available in this article, unless otherwise stated. 


\section{Background}

A mother's diet is important both during and after pregnancy. During pregnancy, maternal diet can influence flavor and food preferences for their infant (e.g., expression of genes related to flavor preferences and greater exposure to flavors through the amniotic fluid and breastmilk) [1]. Maternal diet is also important for the offspring where the shared food environment (i.e., food availability and role modeling) can influence a child's risk for obesity [2,3]. Although mother's overall diet is of importance, vegetables are particularly critical. Vegetable intake during the first year of life is associated with the development of healthy eating habits later in life. Unfortunately, most adults and children fall short of the recommendations. Once complementary feeding has been initiated, $30-40 \%$ of children 6 months and older do not eat a vegetable [4,5]. Early exposure to vegetables may increase the amount and variety of these foods consumed later in childhood [2, 6-10]. Several studies have also found that vegetable intake is a proxy for having a higher diet quality [11-14]. Thus, it is of public health importance to identify changes in vegetable intake between pregnancy and the postnatal period and whether sociodemographic factors predict any of these changes. A better understanding of this possible dietary transition can help identify future intervention targets. In addition, understanding what factors contribute to the transition of improving their vegetable intake or reducing their vegetable intake from pregnancy to postpartum, can better help tailor obesity prevention efforts to pregnant and postpartum women and their children.

Although some studies have explored the transition of a woman's diet from before to during pregnancy, few studies have looked at how their vegetable intake may change after birth. Research suggests that women adopt healthier eating patterns including eating more fruits and vegetables and less fast food during pregnancy [15]. Most often, women who make these changes are older and more educated [16-18], and these healthy changes are not necessarily sustained after delivery [19]. The few studies that have explored what happens to women's diets after pregnancy have focused on describing how macronutrients change from pregnancy to 4 and 5 years postpartum [20, 21]. Exploring changes specifically related to vegetable intake, within a shorter time period after delivery may be important for identifying early intervention targets to improve maternal diet, child obesity risk, and the shared food environment early in life. Additionally, exploring changes in vegetable intake rather than macronutrient intake is informative for developing public health recommendations for pregnant and postpartum women. Therefore, the goal of this study was to 1 ) explore the changes in vegetable intake between pregnancy and the postnatal period in a large, prospective cohort and 2) explore maternal and sociodemographic factors that are associated with these changes. To make our results more relevant to public health recommendations, we described these changes for mother's; that met vegetable recommendations postpartum but not during pregnancy (improved vegetable intake group) as compared to those did not meet vegetable recommendations during pregnancy or postpartum (stable inadequate vegetable intake group) as well as those that that reduced their vegetable intake (reduced their vegetable intake) compared to those that met vegetable recommendations both during pregnancy and postpartum (stable adequate vegetable intake group).

\section{Methods}

We analyzed (2017) secondary data from the Infant Feeding Practice II (IFSP II) study which is a prospective, longitudinal cohort (2005-2012) conducted by the Food and Drug Administration (FDA) and the Centers for Disease Control and Prevention (CDC) in the United States, that followed about 2000 mother-infant pairs from the third trimester of pregnancy throughout the first year of life and then again at 6 years to study a variety of infant feeding practices [22].\} Women $(n=4900)$ were drawn from a national consumer panel during the third trimester of pregnancy, with all data excluding the birth data collected by mail questionnaires. Participating women and their infants could not have a medical condition at birth that would affect feeding and the infant had to have been born after at least 35 weeks' gestation, weigh at least 5 lbs., be a singleton, and not have stayed in intensive care for 3 or more days. After the birth screener, infant-mother pairs were disqualified if the infant was reported to have a serious, long-term health problem that would affect feeding.

A subset of mothers was invited to complete a modified diet history questionnaire (DHQ) prenatally $(n=1444$, response rate $82.2 \%)$ and 4 -months postpartum $(n=1422$, response rate $=79.4 \%)$. This 149 -item questionnaire is a food-frequency measure developed by the National Cancer Institute [22, 23]. Modifications to this questionnaire included changing the time frame of the DHQ from 1 year to 1 month and adding specific foods of interest for pregnant women, including specific types of fish and specific dietary supplements [24].

Per the IFPS II protocol [22], plausible energy intake in the prenatal sample included women with intakes between 671 and $6265 \mathrm{kcal}$ and 606-4539 in the postpartum sample. We analyzed data from the 847 women who completed the DHQ at both time points. Intake (servings/day) of total fruits, vegetables, dairy, sugar-sweetened beverages (SSB), and added sugars (teaspoons) were calculated from the DHQ. Information about infant feeding practices was self-reported by 
mothers 9 times over the infant's first year of life. Additional details about the IFPS II and the prenatal and maternal DHQ subsamples have been previously published [22].

High vegetable intake, defined as meeting the vegetable intake recommendations according to the 2015 Dietary Guidelines for Americans, is both an essential component of dietary quality, favorably associated with pregnancy outcomes, and inadequately consumed among many pregnant [25]. Mothers were categorized into one of four groups: 1) met vegetable recommendations postpartum but not during pregnancy $(n=121)$ (improved vegetable intake group) 2) did not meet vegetable recommendations during pregnancy or postpartum $(n=370)$ (stable inadequate vegetable intake group); 3 ) met vegetable recommendations during pregnancy but not during the postpartum period $(n=123)$ (reduced vegetable intake group) and 4) met vegetable recommendations both during pregnancy and postpartum $(n=233)$ (stable adequate vegetable intake group); and meeting vegetable intake recommendations was defined as $\geq 2.5$ vegetable servings/day after adjustment for total energy intake using the residual method [26] in accordance with the Dietary Guidelines for Americans [25].

\section{Sociodemographic and maternal variables}

We selected available sociodemographic variables that have been associated with maternal dietary intake or quality pre- and post-partum and which were available in IFPS II [27-29]. All questionnaires were developed by the US Food and Drug Administration in collaboration with the Center for Disease Control and members of the working group who had specific expertise in each topic. The prenatal questionnaire was used to collect information about the women's health and health care, and employment status using standard questions related to demographics.

\section{Sociodemographic variables}

Self-reported age was assessed during pregnancy. Maternal participation in the Women Infants and Children (WIC) program and employment status (9 options ranging from unemployed, student, homemaker, part-time, and full-time employment) were measured during pregnancy and in the first year of life. Maternal employment was re-categorized as a 3-level ordinal variable capturing unemployed (fulltime homemaker, disabled student, etc. and not employed, retired and not employed, temporarily unemployed), part-time employment (self-employed, works for someone else part time only), and full-time employment. Family poverty income ratio (PIR) was classified as low $(<185 \%$ of poverty guidelines) or high $(\geq 185 \%$ of poverty guidelines). Maternity leave was computed as the number of weeks of paid leave. After examining missing data in the paid maternity leave variable $(50.2 \%$ missing), we replaced missing values with a ' 0 ' for women who reported anything other than full time employment and had missing data for paid maternity leave since these women would not be eligible for paid leave.

\section{Maternal variables}

Pre-pregnancy BMI was computed from self-reported height and weight just before pregnancy. Participants also reported the current average daily number of cigarettes smoked during pregnancy, whether or not they experienced gestational diabetes with pregnancy $(\mathrm{y} /$ n). Total breastfeeding duration was reported by the mother during the month that she stopped breastfeeding entirely and women also completed the Edinburgh Postpartum Depression Scale, a 10-item validated, broadly utilized tool developed to identify women who have postpartum depression [30].

\section{Statistical analysis}

We examined descriptive characteristics among the four groups of mothers and made comparisons according to our objectives of this study using ANOVA, t-tests and chi-square tests for continuous and categorical variables. We first computed an overall ANOVA to assess differences across the four groups and then did comparisons of the groups according to our established research questions: improved vegetable intake vs. stable inadequate vegetable intake and reduced vegetable intake vs. stable adequate intake. Given our interest in comparing the groups according to those that improved and those that reduced, logistic regression was used. We examined the associations of sociodemographic factors with improved vegetable intake (vs. maintaining a stable inadequate vegetable intake) and reduced vegetable intake (vs. maintaining a stable adequate vegetable intake) adjusted for covariates. Given the wealth of literature exploring socio-economic disparities, in exploratory analyses, we assessed differences in significant predictor variables by income status. To do this, we conducted secondary analyses stratified by poverty income ratio (i.e., higher socioeconomic status (poverty income ratio $\geq 1.85$ ) versus lower socioeconomic status (poverty income ratio $<1.85$ ). We chose this cutoff given the federal nutrition program guidelines such as the WIC program to determine eligibility. We also compared whether other maternal dietary components (i.e., fruit, added sugar, discretionary fat, and dairy) differed between these groups of women to explore how changes in vegetable intake correlated with maternal intake of other dietary components using logistic regression models. Predictors were selected based on their relevance in the previous literature $[27,31,32]$, and age and any variable 
that changed the odds ratio by $10 \%$ or more was included in the final model [33, 34]. All analyses were conducted with SAS v. 9.4.

\section{Results}

Close to one-third of women of women $(28.8 \%, n=244)$ experienced shifts in vegetable intake between pregnancy and postpartum. Less than one quarter of the women did not meet recommendations during pregnancy and subsequently met recommendations during the postpartum period (i.e., improved vegetable intake) $(14.2 \% ; n=$ 121). Similarly, nearly the same number of women either met recommendations during pregnancy, but not during the postpartum period (i.e., reduced vegetable intake) $(14.5 \% ; n=123)$. Overall, more than $40 \%$ of the women did not meet vegetable recommendations during and after pregnancy (43.6\%; $n=370$; stable inadequate) and less than $30 \%$ met recommendations at both time points (27.5\%; $n=233$; stable adequate).

Sociodemographic characteristics did not differ among women who improved their vegetable intake and those in the stable inadequate group. There were significant sociodemographic differences among women who reduced their vegetable intake. Compared to women in the stable adequate group, women who reduced their vegetable intake postpartum were lower income (PIR = $2.7 \pm 1.7$ vs $3.1 \pm 2.4 ; \mathrm{p}=0.04)$ and were more likely to work full time ( $43.5 \%$ vs. $30.0 \% ; \mathrm{p}=0.047$, respectively) (Table 1). Women who improved their vegetable intake had significantly greater mean fruit $(2.5 \pm 0.17$ vs.1.8 \pm $0.2 ; p=0.0006)$ and vegetable $(2.8 \pm 0.10$ vs. $1.3 \pm 0.06$; $p<0.0001)$ intake and reduced sugar intake $(49.8 \pm 0.23$ vs.50.8 $\pm 0.13 \mathrm{~g} ; p<0.0001)$ at both time points compared to women in the stable inadequate group. Those that had reduced vegetable intake, had lower servings of fruit $(1.7 \pm 0.17$ vs. $2.3 \pm 0.12 ; p=0.002)$, vegetables $(2.7 \pm 0.10$ vs. $4.25 \pm 0.07 ; p<0.001)$ and whole grains $2.9 \pm 0.05$ vs. $3.1 \pm 0.04 ; p=0.01$ and higher grams of sugar $(50.0 \pm 0.23$ vs. $48.8 \pm 0.17 ; p<0.0001)$ compared to those in the stable adequate group.

Women who improved their vegetable intake between the pre-and postnatal periods, compared to the stable inadequate group, smoked fewer cigarettes during pregnancy $(0.48 \pm 2.2$ vs. $1.1 \pm 3.9 ; p=0.02)$ (Table 2$)$. Women in the reduced vegetable group intake, compared to the stable adequate group, women had lower pregnancy weight gain ( $32.4 \pm 14.8$ vs. $26.7 \pm 14.7$ lbs.; $p=0.0007)$.

Separate multivariable logistic regression models were used to examine sociodemographic predictors of either improved (versus stable inadequate) and reduced vegetable intake (versus stable adequate). Final models included only significant predictors. No sociodemographic factors were significantly associated with improved vegetable intake. However, greater maternal employment significantly increased the odds of reduced vegetable intake from pregnancy to the postpartum period compared to women who were not employed $(\mathrm{OR}=1.64 ; 95 \% \mathrm{CI}$ 1.14-2.36) in fully adjusted models controlling for age, PIR, smoking, weight gain during pregnancy and paid maternity leave (Table 3).

The strength of association between employment and reduced vegetable intake varied among women of higher socioeconomic status (PIR $\geq 1.85$ ) versus lower socioeconomic status (PIR $<1.85)$. For low income women, an increase in employment status was associated 1.79 times greater odds of reduced vegetable intake from pregnancy to the postpartum period after adjusting for age and gestational weight gain $(\mathrm{OR}=1.79$; 95\%CI $1.03-3.1)$. For those that had higher incomes, there was no significant association between increasing employment status and the odds of reduced vegetable intake $(\mathrm{OR}=1.31$; $95 \% \mathrm{CI}$ 0.94-1.84). However, after adjusting for weeks of paid maternity leave, the association between increasing employment and the odds of reduced vegetable intake was similar between higher and lower income women and no longer statistically significant among lower income women (OR: 1.53; 95\%CI: 0.76-3.05) (Fig. 1).

We also examined dietary predictors of improved and reduced vegetable intake. With respect to improved vegetable intake, in analyses adjusted for age and other dietary components, a 1-unit increase in mean fruit intake was associated with a $12 \%$ increased odds of improved vegetable intake (OR $=1.12 ; 95 \% \mathrm{CI}: 1.00-1.21)$. A 1 -unit increase in mean sugar $(\mathrm{OR}=0.82 ; 95 \% \mathrm{CI}$ : $0.73-0.91)$ or mean dairy $(\mathrm{OR}=0.82$; $95 \% \mathrm{CI}$ : $0.73-0.91)$ was associated with a nearly $20 \%$ reduced odds of improved vegetable intake. A 1-unit increase in mean fruit intake was associated with a $15 \%$ reduced odds of reduced vegetable intake $(p<0.05)$. Conversely, a 1 unit increase in sugar $(\mathrm{OR}=1.31 ; 95 \% \mathrm{CI}$ : $1.17-1.48)$ or dairy $(\mathrm{OR}=1.30 ; 95 \% \mathrm{CI}$ : $1.03-1.63)$ was associated with a $30 \%$ increased odds of reduced vegetable intake (Table 4).

\section{Discussion}

The goal of this study was to 1) explore the changes in vegetable intake between pregnancy and the postnatal period in a large, prospective cohort and 2) explore maternal and sociodemographic factors that are associated with these changes. Within this national sample of pregnant women, we found that $44 \%$ of women were not meeting vegetable recommendations during pregnancy or the postpartum period, $28 \%$ met recommendations at both time points, and the remaining $28 \%$ experienced changes. Notably, $15 \%$ of women who consumed the recommended servings of vegetables during pregnancy transitioned to not meeting the recommendation at 4-months postpartum. Importantly, changes in vegetable intake 
Table 1 Maternal Sociodemographic Characteristics by Energy-Adjusted Change in Vegetable Intake in the IFPS II

\begin{tabular}{|c|c|c|c|c|c|c|}
\hline \multicolumn{7}{|l|}{ Mean (SD) ${ }^{\complement}$ Residual adjusted +2.5} \\
\hline & $\begin{array}{l}\text { Improved Vegetable } \\
\text { Intake }(n=121)\end{array}$ & $\begin{array}{l}\text { Stable Inadequate } \\
(n=370)\end{array}$ & $p$-value & $\begin{array}{l}\text { Reduced Vegetable } \\
\text { Intake }(n=123)\end{array}$ & $\begin{array}{l}\text { Stable Adequate } \\
(n=233)\end{array}$ & $p$-value \\
\hline Age (yrs.) & $28.7(5.25)$ & $28.7(4.98)$ & 0.97 & $29.7(5.23)$ & $30.4(5.28)$ & 0.24 \\
\hline Poverty Income Level & $2.70(1.82)$ & $2.54(1.79)$ & 0.39 & $2.69(1.72)$ & $3.14(2.36)$ & 0.04 \\
\hline \multicolumn{7}{|l|}{ Race (\%) } \\
\hline White & 81.8 & 85.1 & 0.31 & 85.4 & 85.7 & 0.38 \\
\hline Black & 4.1 & 5.2 & 0.31 & 4.9 & 3.5 & 0.38 \\
\hline Hispanic Ethnicity & 9.1 & 4.6 & 0.31 & 4.1 & 6.1 & 0.38 \\
\hline Other & 4.9 & 5.2 & 0.31 & 5.7 & 4.8 & 0.38 \\
\hline \multicolumn{7}{|l|}{ Education (\%) } \\
\hline High school graduate or less & 19.8 & 21.1 & 0.59 & 12.3 & 14.3 & 0.27 \\
\hline College graduate or more & 80.2 & 78.9 & 0.59 & 87.7 & 85.7 & 0.27 \\
\hline \multicolumn{7}{|l|}{ Marital Status (\%) } \\
\hline Married & 82.8 & 78.9 & 0.55 & 84.0 & 87.7 & 0.54 \\
\hline Widowed/Divorced/Separated & 2.6 & 3.1 & 0.55 & 4.2 & 3.1 & 0.54 \\
\hline Never Married & 14.7 & 18.0 & 0.55 & 11.8 & 9.1 & 0.54 \\
\hline Nulliparous (\%) & 27.5 & 25.5 & 0.66 & 29.8 & 31.3 & 0.76 \\
\hline Works for someone else full time $(\%)$ & 33.3 & 39.2 & 0.27 & 43.5 & 30.0 & 0.047 \\
\hline Mother enrollment in WIC 2-mo (\%) & 28.7 & 26.4 & 0.65 & 28.2 & 20.7 & 0.13 \\
\hline Servings of Fruit ${ }^{\mathrm{a}}$ (Mean (SE)) & $2.47(0.17)$ & $1.77(0.20)$ & 0.0006 & $1.70(0.17)$ & $2.29(0.12)$ & 0.002 \\
\hline Servings of Vegetables & $2.76(0.10)^{b}$ & $1.25(0.06)^{\mathrm{a}}$ & $<0.0001$ & $2.70(0.10)^{b}$ & $4.25(0.07)^{c}$ & $<0.0001$ \\
\hline Servings of Dairy & $2.99(0.11)^{\mathrm{ab}}$ & $3.21(0.06)^{\mathrm{a}}$ & 0.08 & $2.93(0.11)^{\mathrm{ab}}$ & $2.71(0.08)^{b}$ & 0.07 \\
\hline Servings of whole grains ${ }^{a}$ & $3.03(0.06)$ & $2.96(0.03)$ & 0.28 & $2.92(0.05)$ & $3.09(0.04)$ & 0.01 \\
\hline Grams of sugar ${ }^{\mathrm{a}}$ & $49.8(0.23)^{b}$ & $50.8(0.13)^{a}$ & $<0.0001$ & $50.0(0.23)^{b}$ & $48.8(0.17)^{c}$ & $<0.0001$ \\
\hline Grams of discretionary fat ${ }^{a}$ & $20.3(1.13)$ & $21.3(0.65)$ & 0.42 & $22.9(1.12)$ & $23.6(0.81)$ & 0.64 \\
\hline
\end{tabular}

a This is an average of the pre-post

b This variable is defined as 0 (fulltime homemaker, disabled student, etc. and not employed, retired and not employed, temporarily unemployed), $1=$ selfemployed, works for someone else part time only, or 2 = works for someone else full time)

Boldface indicates statistical significance $(p<0.05)$

WIC Women Infant and Children

Poverty Income Level: Indicates federal poverty level

c Dietary variables were not considered possible control variables

appear to align with changes in other important food groups such as fruits and added sugars; mean fruit intake was associated increased odds of improved vegetable intake while mean sugar intake was associated with decreased odds of improved vegetable intake. We also found that employed women were more likely to have reduced vegetable intake and that this association differed among high- and low-income women; for low-income women, employment was associated with greater odds of reduced vegetable intake, while there was no significant association among higher income women. However, the association between employment and vegetable intake was similar between higher and lower income women and no longer statistically significant among lower income women after adjusting for paid maternity leave.

Many of our results are consistent with existing literature. For example, overall, we found that almost half of women in this cohort are not meeting vegetable recommendations during and after pregnancy. This is similar to other studies whereby overall diet quality among both pregnant and non-pregnant women is suboptimal, with high intakes of sugary drinks, and low intakes of nutrient dense foods such as vegetables $[35,36]$. Although previous studies in pregnant and postpartum women are limited in number, one showed that maternal macronutrient intake did not change drastically during this time period, which differs from our food-based analysis, where $28 \%$ of women improved or reduced their vegetable intake from the pregnancy to postpartum [20]. Findings from a qualitative study suggest that mothers believe they change their diets and eating habits after the birth of their child and that they turn towards unhealthier dietary habits [38]. The primary reason for changing their diet was feeling responsible for their 
Table 2 Maternal Characteristics by Energy-Adjusted Change in Vegetable Intake in the IFPS II

\begin{tabular}{|c|c|c|c|c|c|c|}
\hline \multicolumn{7}{|l|}{ Mean (SD) ${ }^{* *}$ Residual adjusted +2.5} \\
\hline & $\begin{array}{l}\text { Improved Vegetable } \\
\text { Intake }(n=121)\end{array}$ & $\begin{array}{l}\text { Stable Inadequate } \\
(n=370)\end{array}$ & $p$-value & $\begin{array}{l}\text { Reduced Vegetable } \\
\text { Intake }(n=123)\end{array}$ & $\begin{array}{l}\text { Stable Adequate } \\
(n=233)\end{array}$ & $p$-value \\
\hline Pre-pregnancy BMI & $26.0(5.60)$ & $25.8(6.33)$ & 0.82 & $27.3(6.86)$ & $26.6(6.61)$ & 0.36 \\
\hline Pregnancy weight gain (lb) & $30.9(12.3)$ & $30.2(12.48)$ & 0.62 & $26.7(14.70)$ & $32.4(14.8)$ & 0.0007 \\
\hline Cigarettes smoked & $0.48(2.20)$ & $1.14(3.89)$ & 0.02 & $0.82(2.91)$ & $0.40(2.13)$ & 0.16 \\
\hline Breastfeeding Duration (months) & $5.9(4.8)$ & $5.6(4.5)$ & 0.62 & $6.2(5.1)$ & $6.80(4.8)$ & 0.28 \\
\hline Paid and unpaid maternity leave (wks.) & $8.95(13.2)$ & $9.41(8.58)$ & 0.80 & $10.1(7.09)$ & $8.70(8.18)$ & 0.28 \\
\hline GDM in pregnancy (\%) & 4.59 & 6.49 & 0.47 & 11.1 & 7.6 & 0.29 \\
\hline PPD Score & $8.08(3.15)$ & $8.41(3.22)$ & 0.35 & $8.80(3.27)$ & $8.37(3.39)$ & 0.27 \\
\hline $\begin{array}{l}\text { Received Information about diet from } \\
\text { health professional }\end{array}$ & 83.1 & 80.9 & 0.61 & 82.8 & 84.1 & 0.76 \\
\hline Received Information about diet from WIC & 30.8 & 30.2 & 0.91 & 28.9 & 28.3 & 0.91 \\
\hline
\end{tabular}

Boldface indicates statistical significance $(p<0.05)$

GDM Gestational Diabetes Mellitus, PPD Postpartum Depression

Table 3 Sociodemographic Predictors of Reduced and Improved Vegetable Intake from the Pre- to Post-natal period

\begin{tabular}{|c|c|c|}
\hline & \multicolumn{2}{|l|}{ Odds Ratio (95\% Cl) } \\
\hline & $\begin{array}{l}\text { Reduced Vegetable } \\
\text { Intake vs. Stable } \\
\text { Adequate }\end{array}$ & $\begin{array}{l}\text { Improved Vegetable } \\
\text { Intake vs. Stable } \\
\text { Inadequate }\end{array}$ \\
\hline Employment $^{a}$ & $1.31(1.01-1.70)$ & $0.92(0.72-1.17)$ \\
\hline \multicolumn{3}{|l|}{ Model 1} \\
\hline Employment $^{\mathrm{a}}$ & $1.33(1.02,1.74)$ & $0.90(0.70-1.15)$ \\
\hline Age & $0.97(0.93-1.02)$ & $1.02(0.98-1.07)$ \\
\hline \multicolumn{3}{|l|}{ Model 2} \\
\hline Employment $^{\mathrm{a}}$ & $1.51(1.14,2.02)$ & $0.87(0.67-1.14)$ \\
\hline Age & $0.98(0.94-1.03)$ & $1.02(0.97-1.06)$ \\
\hline Poverty Income Ratio & $0.84(0.73-0.97)$ & $1.05(0.92-1.20)$ \\
\hline \multicolumn{3}{|l|}{ Model 3} \\
\hline Employment $^{\mathrm{a}}$ & $1.52(1.13-2.04)$ & $0.85(0.65-1.11)$ \\
\hline Age & $0.98(0.93-1.03)$ & $1.02(0.97-1.07)$ \\
\hline PIR & $0.87(0.75-1.00)$ & $1.07(0.93-1.23)$ \\
\hline Weight gain in pregnancy & $0.97(0.96-0.99)$ & $1.01(0.99-1.03)$ \\
\hline \multicolumn{3}{|l|}{ Final Model } \\
\hline Employment $^{a}$ & $1.64(1.14,2.36)$ & $0.88(0.64-1.22)$ \\
\hline Age & $0.98(0.93,1.03)$ & $1.03(0.98-1.08)$ \\
\hline Smoking & $1.02(0.93,1.13)$ & $0.96(0.89-1.04)$ \\
\hline PIR & $0.88(0.76,1.03)$ & $1.01(0.86-1.17)$ \\
\hline Weight gain in pregnancy & $0.97(0.96,0.99)$ & $1.01(0.99-1.03)$ \\
\hline $\begin{array}{l}\text { Weeks of paid maternity } \\
\text { leave }\end{array}$ & $0.96(0.89,1.03)$ & $0.98(0.92-1.05)$ \\
\hline
\end{tabular}

a This variable is defined as 0 (fulltime homemaker, disabled student, etc. and not employed, retired and not employed, temporarily unemployed), $1=$ selfemployed, works for someone else part time only, or $2=$ works for someone else full time)

PIR Poverty Income Ratio baby's digestive discomfort via their breastmilk, which narrowed their range of foods, time scarcity for food preparation and eating and disruptions in their usual eating routines. We found that the odds of reduced vegetable intake was greater with increasing intake of added sugar and dairy, supporting the hypothesis that energy-dense convenience foods may substitute for more nutrient-dense choices. Our findings suggest that there is a window of opportunity to help women maintain or improve their diet quality as they transition to becoming a parent.

The complex association we describe between maternal employment, socioeconomic status, paid leave, and diet quality warrants further exploration. Increasing maternal employment was associated with a $60 \%$ greater odds of reduced vegetable intake. Our findings are consistent with one study whereby mothers felt that going back to work reduced their diet quality [38]. This study, however, did not explore differences by income, and was conducted among Danish mothers who experience longer periods of maternity leave. We found that there was no association between employment status and reduced vegetable intake among higher income women whereas among lower income women increasing employment was associated with a greater odds of reduced vegetable intake from pregnancy to the postpartum period. However, after further adjustment for weeks of paid maternity leave, this association was similar between higher and lower income women and no longer statistically significant among lower income women suggesting that differential access to this resource may contribute to socioeconomic disparities in vegetable intake among pregnant women.

Maternal employment may be related to reduced vegetable intake among lower income women because of additional challenges associated with significant financial 


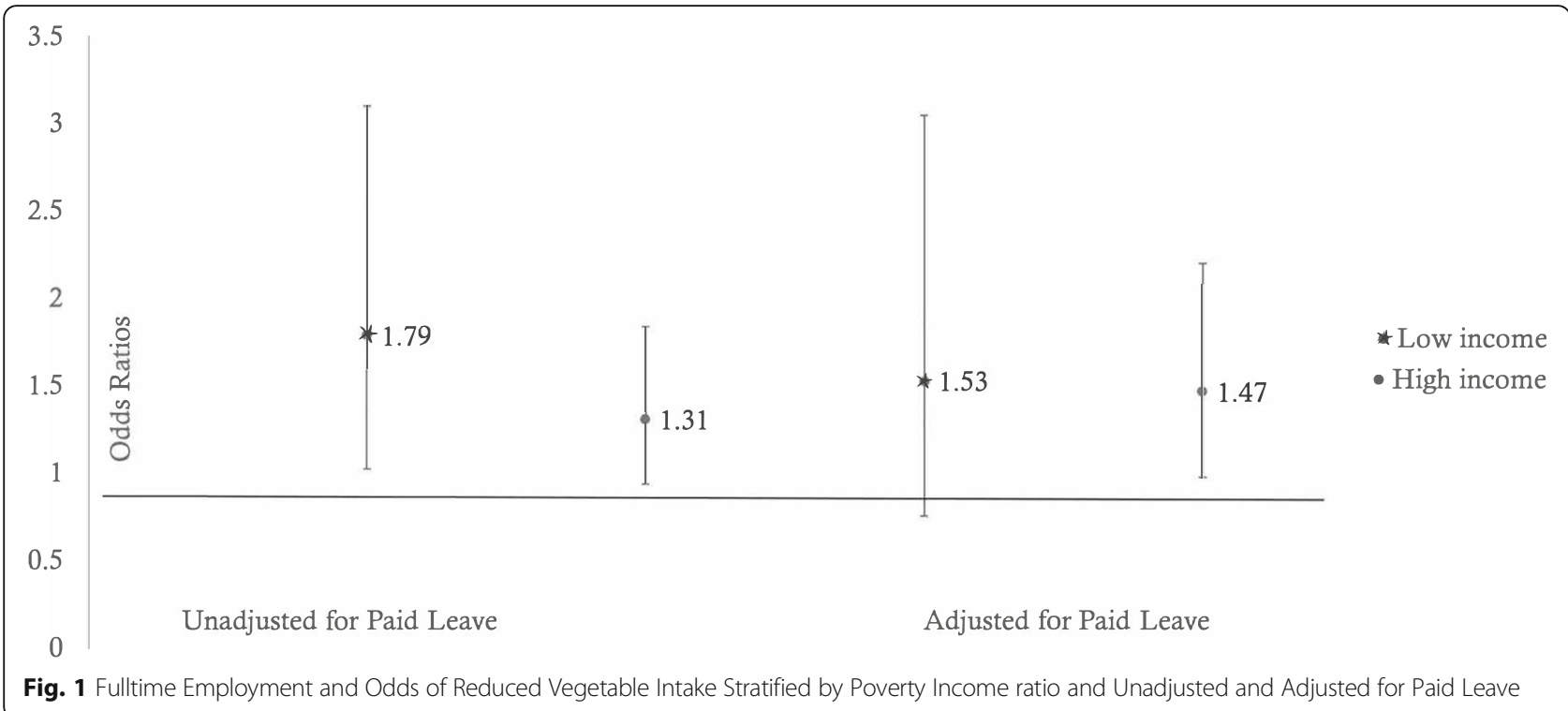

barriers. Employed mothers perceive that they have less time to prepare and procure meals and that changing demands on their time promotes a shift towards consuming more commercially prepared and fast foods [39]. Mothers also report psychological effects of employment such as higher levels of stress and depression, which may adversely influence diet quality [40]. This may be exacerbated among lower income women who both work for lower wages and manage other stressors associated with balancing financial strain and parenthood [41]. There may be differential access to nutrient-dense and affordable convenience foods for low-income women.

Table 4 Maternal and Dietary Predictors of Reduced and Improved Maternal Vegetable Intake from the Pre- to Post-natal period

\begin{tabular}{|c|c|c|}
\hline & \multicolumn{2}{|l|}{ Odds Ratio (95\% Cl) } \\
\hline & $\begin{array}{l}\text { Reduced Vegetable } \\
\text { Intake vs. Stable } \\
\text { Adequate }\end{array}$ & $\begin{array}{l}\text { Improved Vegetable } \\
\text { Intake vs. Stable } \\
\text { Inadequate }\end{array}$ \\
\hline Mean fruit intake & $0.81(0.71-0.94)$ & $1.18(1.07,1.31)$ \\
\hline \multicolumn{3}{|l|}{ Model 1} \\
\hline Mean fruit intake & $0.81(0.71-0.94)$ & $1.18(1.07-1.31)$ \\
\hline Age & $0.97(0.93-1.02)$ & $1.00(0.96-1.05)$ \\
\hline \multicolumn{3}{|l|}{ Model 2} \\
\hline Mean fruit intake & $0.83(0.72-0.97)$ & $1.14(1.03-1.27)$ \\
\hline Age & $0.98(0.94-1.03)$ & $1.00(0.95-1.04)$ \\
\hline Mean sugar & $1.29(1.14-1.45)$ & $0.84(0.76-0.93)$ \\
\hline \multicolumn{3}{|l|}{ Final Model } \\
\hline Mean fruit intake & $0.85(0.73-0.98)$ & $1.12(1.00,1.24)$ \\
\hline Age & $0.98(0.94-1.03)$ & $0.99(0.95-1.04)$ \\
\hline Mean sugar & $1.31(1.17-1.48)$ & $0.82(0.73-0.91)$ \\
\hline Mean dairy & $1.30(1.03-1.63)$ & $0.81(0.67-0.98)$ \\
\hline
\end{tabular}

Furthermore, low-income women may disproportionately participate in occupations that provide limited autonomy and power to employees, disempowering them to continue prioritizing more healthful dietary choices upon return to work [42]. In other words, the food-coping strategies available to lower income, fully employed women may differ from their higher income counterparts [41].

Although it is well established that food availability, access, cost, cultural preferences, and social roles are all important determinants of food choice [43], little research has explored modifiable factors that could favorably influence food choice without changing these underlying determinants. Our research adds to this by considering the impact of temporary support systems, like paid maternity leave, to support healthful food choices. Our finding that paid maternity leave appears to eliminate the disparity in vegetable intake between employed higher and lower income pregnant women after birth, highlights the importance of this temporary support. One study similarly found that the dietary intake of working women with children did not appear to be influenced by hours of employment [44], suggesting that perhaps it is not employment per se that is associated with reduced diet quality during the transition to motherhood but rather ensuring that that they have enough support to return to work.

Our study has some limitations that should be discussed. First, the IFPS II data was collected in 2007 and was among predominately White, educated, and non-diverse, limiting the generalizability to other race/ ethnicities where rates of obesity are higher, and likely underestimating the strength of association observed. 
Diet was self-reported, which is subject to under or over reporting; however, the DHQ is considered a reasonably valid and reliable tool for this population. Additionally, height and weight were self-reported, which may have attenuated the associations between maternal BMI, gestational weight gain, and changes in vegetable intake. Finally, women were drawn from a self-selected consumer panel and not a random sample; hence, they may not be representative of the US population, although the sample was well distributed throughout the United States.

Several strengths of our study include the large national sample, two diet collection periods, and detailed information on sociodemographic and maternal characteristics. Additionally, examining changes in vegetable intake between pregnancy and postpartum provides unique insight into a critical window when a woman's diet may change, which is important for the development of nutrition policy. While pregnant women may feel motivated and supported to make healthful food choices during pregnancy [37], our results suggest that additional support systems may be needed in the period immediately postpartum - especially among lower income women.

\section{Conclusion}

Establishing a healthy diet as a woman transitions to becoming a mother is critical not only for her own health but for that of her child. While our results suggest that many pregnant and post-partum women are not consuming the recommended servings of vegetables each day, we also highlight a group of women for whom additional support could help them maintain adequate prenatal vegetable intake into the postpartum period. Systemic barriers including socioeconomic disadvantage are difficult to structurally change, and our results provide preliminary evidence for short-term support that may help reduce health disparities.

\footnotetext{
Abbreviations

DHQ: Diet history questionnaire; IFPSII: Infant Feeding Practice Study II cohort; OR: Odds ratio; PIR: Poverty income ratio; WIC: Women, Infants and Children Program
}

\section{Acknowledgements}

None.

\begin{abstract}
Authors' contributions
All the authors contributed to the various stages of this study. AT contributed to the study design, and drafted the manuscript. JK, KM, DD and AF contributed to design of the study, and helped revise the manuscript. MV contribute to the study design, completed the statistical analysis, and substantially contributed to manuscript review. All the authors read and commented on the drafts and approved of the final version for submission.
\end{abstract}

\section{Funding}

Dr. Tovar and Vadiveloo are supported by the Agricultural Experiment Station Fund Source: Hatch Regional: RI0019-W3005 and RI0018-NC1196, respectively.

\section{Availability of data and materials}

Although the datasets used and/or analyzed during the current study are publicly available, an email should be sent to the following email address to request access: ifps@cdc.gov.

\section{Ethics approval and consent to participate}

All questionnaires, other materials sent to respondents, and procedures were approved by the FDA's Research Involving Human Subjects Committee (the institutional review board) and the US Office of Management and Budget for the original study. For this secondary data analysis, an approval letter was received in April 2017, from the Division of Nutrition, Physical Activity, and Obesity, United States Centers for Disease Control and Prevention in order to analyze and publish the data.

\section{Consent for publication}

Not applicable.

\section{Competing interests}

The authors declare that they have no competing interests.

\section{Author details}

1Department of Nutrition and Food Sciences, University of Rhode Island, 41 Lower College Road, Kingston, RI 02881, USA. ²Department of Pediatrics, School of Medicine, University of Colorado Anschutz Medical Campus, Aurora, CO, USA. ${ }^{3}$ Department of Human Development and Family Studies, University of Rhode Island, Kingston, RI, USA. ${ }^{4}$ Department of Epidemiology, Brown University, Providence, RI, USA. 'Department of Epidemiology,

Colorado School of Public Health, University of Colorado Anschutz Medical Campus, Aurora, CO, USA.

Received: 13 December 2018 Accepted: 4 June 2019

Published online: 26 July 2019

\section{References}

1. Ventura AK, Worobey J. Early influences on the development of food preferences. Curr Biol. 2013;23(9):R401-8.

2. Birch LL. Development of food preferences. Annu Rev Nutr. 1999;19:41-62.

3. Reilly JJ, Armstrong J, Dorosty AR, Emmett PM, Ness A, Rogers I, Steer C, Sherriff A. Avon longitudinal study of $\mathrm{P}$, children study T: early life risk factors for obesity in childhood: cohort study. BMJ. 2005;330(7504):1357.

4. Siega-Riz AM, Deming DM, Reidy KC, Fox MK, Condon E, Briefel RR. Food consumption patterns of infants and toddlers: where are we now? J Am Diet Assoc. 2010;110(12 Suppl):S38-51.

5. Fox MK, Condon E, Briefel RR, Reidy KC, Deming DM. Food consumption patterns of young preschoolers: are they starting off on the right path? J Am Diet Assoc. 2010;110(12 Suppl):S52-9.

6. Skinner JD, Carruth BR, Bounds W, Ziegler P, Reidy K. Do food-related experiences in the first 2 years of life predict dietary variety in school-aged children? J Nutr Educ Behav. 2002;34(6):310-5.

7. Mallan KM, Fildes A, Magarey AM, Daniels LA. The relationship between number of fruits, vegetables, and noncore foods tried at age 14 months and food preferences, dietary intake patterns, fussy eating behavior, and weight status at age 3.7 years. J Acad Nutr Diet. 2016;116(4):630-7.

8. Lange C, Visalli M, Jacob S, Chabanet C, Schlich P, Nicklaus S. Maternal feeding practices during the first year and their impact on infants', acceptance of complementary food. Food Qual Prefer. 2013;29(2):89-98.

9. Blossfeld I, Collins A, Boland S, Baixauli R, Kiely M, Delahunty C. Relationships between acceptance of sour taste and fruit intakes in 18-month-old infants. Brit J Nutr. 2007;98(5):1084-91.

10. Cooke LJ, Wardle J, Gibson EL, Sapochnik M, Sheiham A, Lawson M. Demographic, familial and trait predictors of fruit and vegetable consumption by pre-school children. Public Health Nutr. 2004;7(2):295-302.

11. Aljadani HM, Patterson A, Sibbritt D, Hutchesson MJ, Jensen ME, Collins CE. Diet quality, measured by fruit and vegetable intake, predicts weight change in young women. J Obes. 2013;2013:525161.

12. Loftfield $E, Y i S$, Immerwahr $S$, Eisenhower D. Construct validity of a singleitem, self-rated question of diet quality. J Nutr Educ Behav. 2015;47(2):181-7.

13. Skreden M, Bere E, Sagedal LR, Vistad I, Overby NC. Changes in fruit and vegetable consumption habits from pre-pregnancy to early pregnancy among Norwegian women. BMC Pregnancy Childbirth. 2017;17(1):107. 
14. Vinther JL, Conklin Al, Wareham NJ, Monsivais P. Marital transitions and associated changes in fruit and vegetable intake: findings from the population-based prospective EPIC-Norfolk cohort, UK. Soc Sci Med. 2016; 157:120-6.

15. Hillier SE, Olander EK. Women's dietary changes before and during pregnancy: a systematic review. Midwifery. 2017:49:19-31.

16. Crozier SR, Robinson SM, Borland SE, Godfrey KM, Cooper C, Inskip HM, Group SWSS. Do women change their health behaviours in pregnancy? Findings from the Southampton Women's survey. Paediatr Perinat Epidemiol. 2009;23(5):446-53.

17. Skreden M, Bere E, Sagedal LR, Vistad I, Overby NC. Changes in beverage consumption from pre-pregnancy to early pregnancy in the Norwegian fit for delivery study. Public Health Nutr. 2015;18(7):1187-96.

18. Crozier SR, Robinson SM, Godfrey KM, Cooper C, Inskip HM. Women's dietary patterns change little from before to during pregnancy. J Nutr. 2009; 139(10):1956-63.

19. Olson CM. Tracking of food choices across the transition to motherhood. J Nutr Educ Behav. 2005;37(3):129-36.

20. Brion M-JA, Ness AR, Rogers I, Emmett P, Cribb V, Davey Smith G, Lawlor DA. Maternal macronutrient and energy intakes in pregnancy and offspring intake at $10 \mathrm{y}$ : exploring parental comparisons and prenatal effects. Am J Clin Nutr. 2010;91(3):748-56.

21. Murrin C, Shrivastava A, Kelleher CC, Lifeways cross-generation cohort study steering G. Maternal macronutrient intake during pregnancy and 5 years postpartum and associations with child weight status aged five. Eur J Clin Nutr. 2013;67(6):670-9.

22. Fein SB, Labiner-Wolfe J, Shealy KR, Li R, Chen J, Grummer-Strawn LM. Infant feeding practices study II: study methods. Pediatrics. 2008;122(Suppl 2):S28-35.

23. Thompson FE, Subar AF, Brown CC, Smith AF, Sharbaugh CO, Jobe JB, Mittl B, Gibson JT, Ziegler RG. Cognitive research enhances accuracy of food frequency questionnaire reports: results of an experimental validation study. J Am Diet Assoc. 2002;102(2):212-25.

24. Infant feeding practices study II measures [https://www.cdc.gov/breastfeeding/ data/ifps/questionnaires.htm].

25. US Department of Health and Human Services. US Department of Agriculture: Dietary guidelines for Americans, 2015-2020. 8th ed Washington, DC: U.S: government printing office; 2015.

26. Willett WC, Howe GR, Kushi LH. Adjustment for total energy intake in epidemiologic studies. Am J Clin Nutr. 1997;65(4):1220S-8S.

27. Shapiro AL, Kaar JL, Crume TL, Starling AP, Siega-Riz AM, Ringham BM Glueck DH, Norris JM, Barbour LA, Friedman JE, et al. Maternal diet quality in pregnancy and neonatal adiposity: the healthy start study. Int J Obes. 2016; 40(7):1056.

28. Sauder KA, Starling AP, Shapiro AL, Kaar JL, Ringham BM, Glueck DH, Leiferman JA, Siega-Riz AM, Dabelea D. Diet, physical activity and menta health status are associated with dysglycaemia in pregnancy: the healthy start study. Diabet Med. 2016;33(5):663-7.

29. Zulyniak MA, de Souza RJ, Shaikh M, Desai D, Lefebvre DL, Gupta M, Wilson J, Wahi G, Subbarao P, Becker AB, et al. Does the impact of a plant-based diet during pregnancy on birth weight differ by ethnicity? A dietary pattern analysis from a prospective Canadian birth cohort alliance. BMJ Open. 2017; 7(11):e017753.

30. Cox JL, Holden JM, Sagovsky R. Detection of postnatal depression Development of the 10-item Edinburgh postnatal depression scale. Br J Psychiatry. 1987;150:782-6.

31. Poon AK, Yeung E, Boghossian N, Albert PS, Zhang C. Maternal dietary patterns during third trimester in association with birthweight characteristics and early infant growth. Scientifica (Cairo). 2013;2013:786409.

32. van den Broek M, Leermakers ET, Jaddoe WW, Steegers EA, Rivadeneira F, Raat H, Hofman A, Franco OH, Kiefte-de Jong JC. Maternal dietary patterns during pregnancy and body composition of the child at age $6 \mathrm{y}$ : the generation R study. Am J Clin Nutr. 2015;102(4):873-80.

33. Hosmer D, Lemeshow S, Sturdivant R. Applied logistic regression: John Wiley \& Sons, Inc; 2000

34. Kamangar F. Confounding variables in epidemiologic studies: basics and beyond. Arch Iran Med. 2012;15(8):508-16.

35. Bodnar LM, Siega-Riz AM. A diet quality index for pregnancy detects variation in diet and differences by sociodemographic factors. Public Health Nutr. 2002;5(6):801-9.
36. Hiza HA, Casavale KO, Guenther PM, Davis CA. Diet quality of Americans differs by age, sex, race/ethnicity, income, and education level. J Acad Nutr Diet. 2013;113(2):297-306.

37. Hillier SE, Olander EK. Women's dietary changes before and during pregnancy: a systematic review. Midwifery. 2017;49:19-31.

38. Aschemann-Witzel J. Danish mothers' perception of the healthiness of their dietary behaviors during transition to parenthood. J Fam Issues. 2013;34(10): 1335-55.

39. Sliwa SA, Must A, Perea F, Economos CD. Maternal employment, acculturation, and time spent in food-related behaviors among Hispanic mothers in the United States. Evidence from the American time use survey. Appetite. 2015;87:10-9.

40. Oddo VM, Surkan PJ, Hurley KM, Lowery C, de Ponce S, Jones-Smith JC. Pathways of the association between maternal employment and weight status among women and children: qualitative findings from Guatemala. Matern Child Nutr. 2017

41. Blake CE, Wethington E, Farrell TJ, Bisogni CA, Devine CM. Behavioral contexts, food-choice coping strategies, and dietary quality of a multiethnic sample of employed parents. J Am Diet Assoc. 2011;111(3):401-7.

42. Devine CM, Connors MM, Sobal J, Bisogni CA. Sandwiching it in: spillover of work onto food choices and family roles in low- and moderate-income urban households. Soc Sci Med. 2003:56(3):617-30.

43. Leng G, Adan RAH, Belot M, Brunstrom JM, de Graaf K, Dickson SL, Hare T, Maier S, Menzies J1, Preissl H, Reisch LA, Rogers PJ. The determinants of food choice. Smeets PAM. Proc Nutr Soc. 2017;76(3):316-327.

44. Miller J, Chan L, Mehta K, Roberts R, Dickinson KM, Yaxley A, Matwiejczyk L, Thomas J, Wray A, Jackson K, et al. Dietary intake of working women with children does not appear to be influenced by hours of employment: a secondary analysis of the Australian health survey (2011-2013). Appetite. 2016;105:106-13.

\section{Publisher's Note}

Springer Nature remains neutral with regard to jurisdictional claims in published maps and institutional affiliations.

Ready to submit your research? Choose BMC and benefit from:

- fast, convenient online submission

- thorough peer review by experienced researchers in your field

- rapid publication on acceptance

- support for research data, including large and complex data types

- gold Open Access which fosters wider collaboration and increased citations

- maximum visibility for your research: over $100 \mathrm{M}$ website views per year

At $\mathrm{BMC}$, research is always in progress.

Learn more biomedcentral.com/submissions 